\title{
MODELLING IN HBIM TO DOCUMENT MATERIALS DECAY BY A THEMATIC MAPPING TO MANAGE THE CULTURAL HERITAGE: THE CASE OF “CHIESA DELLA PIETÀ” IN FERMO
}

\author{
E. S. Malinverni ${ }^{1 *}$, F. Mariano ${ }^{1}$, F. Di Stefano ${ }^{1}$, L. Petetta ${ }^{1}$, F. Onori ${ }^{1}$ \\ ${ }^{1}$ Università Politecnica delle Marche, Dipartimento di Ingegneria Civile, Edile e dell'Architettura, 60100 Ancona, Italy - \\ (e.s.malinverni, f.mariano)@staff.univpm.it; f.distefano@pm.univpm.it; (leonardo.petetta, federica.onori92)@gmail.com
}

KEY WORDS: cultural heritage, decay, restoration, modelling, HBIM, data management

\begin{abstract}
:
Relevant, historically, it is the role of the Diocese of Fermo (Italy) in the Vatican organization dedicated to vast ecclesiastical patrimony on the territory of the Marche region. In this context, for the peculiarity of its identity and its property, the object of this study is the "Chiesa della Pietà". This research starts with the photogrammetric survey to document and analyse the existing condition of the church. The data acquisition provides many scans following a network schema and the photographic survey allows to create orthoimages to make more realistic the 3D representation. Once acquired the geometric and material survey, a series of investigations have been carried out to assess the surface degradation and the material decay of the external façades and internal environments. Furthermore, some structural problems have been occurred, investigating and verifying the presence of advanced stages of deterioration of the wooden structures and the restoration of these structural elements must be mandatory. To take under control the decay and to propose a restoration step, we have arranged the 3D model in HBIM software with different LOD, according to the BIM Forum Level of Development Specification (2016), suitable to develop a well-structured information system. Before the 3D modelling phase, a decomposition of the building is useful to implement a semantic classification of the architectural elements. Basing on a hierarchy of classes and subclasses, the dedicated database organizes the building components assigning an ID-code to the features, putting in evidence materials decay by a thematic mapping.
\end{abstract}

\section{INTRODUCTION}

Many projects concerning the protection, conservation, restoration, and dissemination of Cultural Heritage $(\mathrm{CH})$ are being carried out due to its growing interest as a driving force of socio-economic development. The realization of digital 3D models allows the planning and management of these projects in a remote and decentralized system. There are many software tools to perform the modelling and to manage documentation for these artefacts. The complex modelling of cultural heritage through commercial BIM software leads to the consideration of the concept of Heritage Building Information Modelling (HBIM), which pursues the modelling of architectural elements, according to artistic, historical, and constructive typologies. In addition, HBIM is an emerging technology that enables us to understand, document and virtually reconstruct the built heritage (Lopez el al., 2018).

The work presented in these pages outlines a novel approach of HBIM implementation to manage the $\mathrm{CH}$ in field of restoration, to document the materials decay through a thematic mapping as a semantic representation.

The next paragraph introduces the monument in exam, that is the "Chiesa della Pietà" in Fermo (Italy), describing its architecture and giving historic information about it. Section 3 gives a brief explanation, by the literature, of the use of HBIM for built heritage to show the advantages of this information system. Section 4 will be dedicated to the description of the whole workflow pipeline and to the discussion of the steps of HBIM approach to build a unique database useful to assign to the architectural elements their characteristics. Then we chose the façade of the church to apply an example of 3D decay mapping managed in HBIM environment. Some remarks offered by our approach are outlined in the conclusion.

\section{HISTORICAL RESEARCH}

Relevant, historically, is the role of the Diocese of Fermo in the Vatican organization dedicated to the territory of the Marche region and it is not surprising that here there is a vast patrimony belonging just to the ecclesiastical community. Interesting in this context, for the peculiarity of its identity and its property, is the "Chiesa della Pietà" object of this study: this was erected in the XVI century by a lay association called "Arciconfraternita della Pietà" with the aim of assisting the needy and is, to date, still owned by the same archconfraternity (Trebbi, 2003; Maranesi, 2002).

Of the original construction (nominated as Church of San Bartolomeo) we have news of its existence as early as 1192 but unfortunately no further information is available. However, through the research and study of the documents (some unpublished) maintained in the Archiepiscopal Archives of Fermo it was possible to discovery the constructive path of the artefact concerning the following periods. In particular, the manuscripts, concerning pastoral visits (Fermo, Archivio Arcivescovile, 1573; Fermo, Archivio Arcivescovile, 1838) and inventories (Fermo, Archivio Arcivescovile, 1728; Fermo, Archivio Arcivescovile, 1772), belonging to the "Arciconfraternita della Pietà" provided an evolutionary picture of the architectural complex of the Church (including ornaments and furnishings) up to the present configuration.

The main façade (Figure 1) is composed of two completely different architectural styles that clearly distinguish the most

\footnotetext{
* Corresponding author
} 
ancient basal body of the front from the top of the same that evidence, instead, the awkward elevation created between 1772 and 1838 in order to increase the internal volume of the liturgical hall (Fermo, Archivio Arcivescovile, 1838; Fermo, Archivio Arcivescovile, 1772).

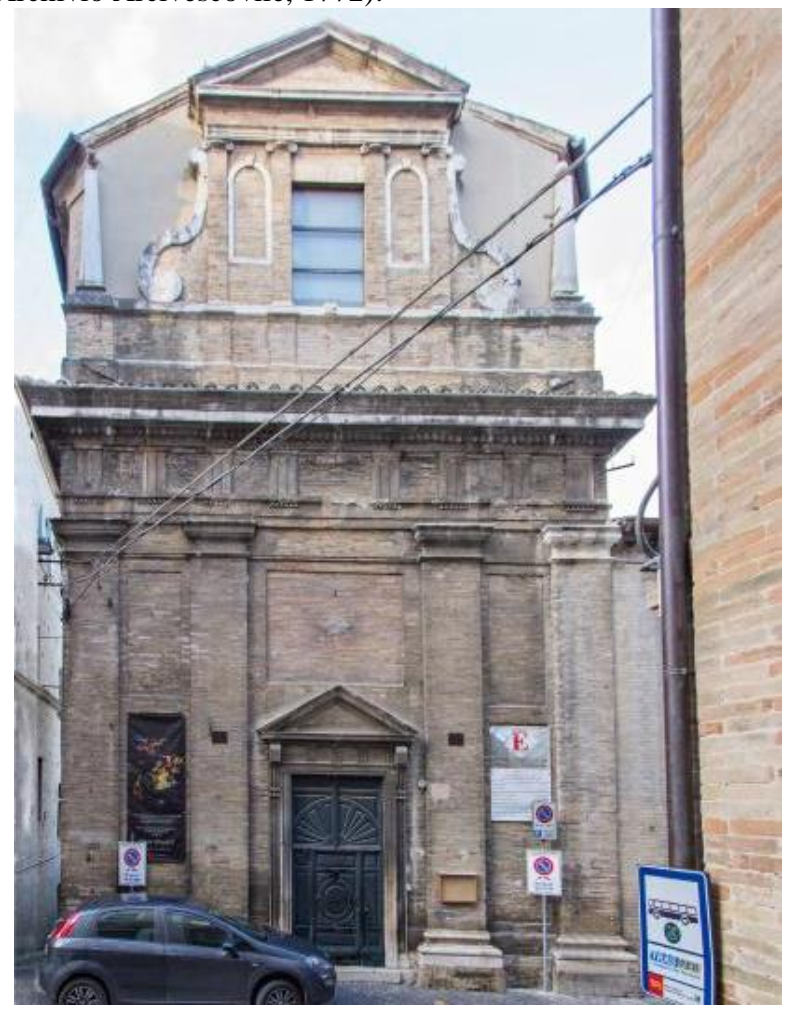

Figure 1. Main facade of the "Chiesa della Pietà" (by Onori F.)

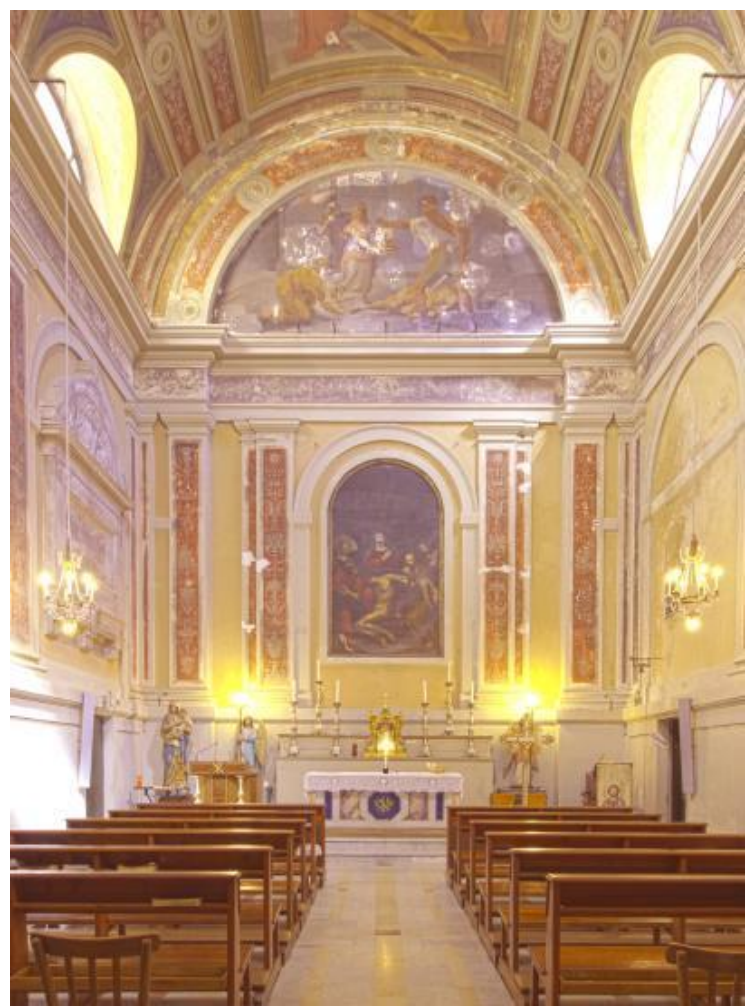

Figure 2. Internal view of the "Chiesa della Pietà" (by Onori F.)
The oldest part of the façade, which is made up of four sturdy Doric columns on which a trabeation protrudes, was designed by the architect Oliviero Spinucci and was performed by the stonemason "mastro Nicolò Veneziano" in the first step and by the "mastro Venturi" in the second one (1606) (Maranesi, 2002).

The internal space of the Church (Figure 2) is articulated into a single central nave where the main altar is placed in opposite position to the entrance door and two minor altars are placed adjacent to the side walls. Near the left altar there is also a funeral mausoleum built in 1851 by the roman sculptor Ignazio Jacometti. The interior space is entirely frescoed and decorated with pilasters, arches and cornices that are repeated creating a well-defined rhythmic motif. Of value is the ceiling of the nave made with a barrel vault also completely frescoed with depictions inspired by the life of St. John the Baptist. The decorative part is attributed to Pietro Lucchi, while the frescoes are the work of the painter Giacomo Cordella exponent of the school of purists (1872) (Maranesi, 2002).

\section{HBIM FOR CULTURAL HERITAGE}

Tangible cultural heritage, particularly immovable assets (monuments, archaeological sites, and so on), is the main subject of application in the new approaches. A structured digital 3D model as part of the architectural heritage improvement process is an urgent need, nowadays. Moreover, the digital 3D model must be converted into a crucial reference frame for the understanding and monitoring of documentation, thus creating a data source (graphics and semantics) that is suitable for assisting in conservation, restoration, and reconstruction projects (Penttilä et al., 2007)

3D scanning and photogrammetric techniques are particularly relevant for accelerating spatial data collection from existing buildings. Laser scanner provides a precise geometric knowledge of 3D objects in a short time, in the form of millions of points, with geometric coordinates (Gómez-García-Bermejo, 2013). Moreover, colour and material information can also be integrated or mapped by using digital reflex camera. A series of steps, such as cleaning and filtering the "noise" of the point cloud, is required before the use, obtaining a final point cloud that aims to preserve the original complexity of the documented heritage.

The processed point cloud can be a starting point to give a product suitable for Building Information Modelling (BIM) platforms, adopted in recent years as a new paradigm for documentation and data management of existing assets, especially of the built historical monuments (Akbarnezhad et al, 2014).

It is important to note that the libraries and tools of the BIM platforms focus on the design and construction of new buildings with simple, regular, and standardized objects (Bryde et al., 2013). For this reason, the virtual and detailed reconstruction of cultural-historical heritage has revealed some limitations of BIM platforms, such as the unavailability of historical parametric object libraries and the lack of tools for managing complex, irregular shapes that are obtained from point clouds.

According to Murphy et al., (2009) and Volk et al., (2014), once the parametric objects are modelled using the architectural historical documentation and the laser scanning data, the libraries of the modelled elements should be generated, encapsulating the concept of Heritage Building Information Modelling (HBIM).

Historic buildings have different characteristics compared to new buildings. Each historic building is different from the other and has characteristics and singularities that make it a unicum. 
The lifecycle of an historic building is cyclical for the periodic and recurring activities for its maintenance and restoration but also for managing several multi-temporal information. In addition, the whole history of the building must be considered and added to the information about the actual state (Bruno, 2017).

Basing on these main considerations, it's clear that HBIM implementation cannot follow a standard approach, but it needs to understand the Level of Development (LOD) that we can obtain, basing on acquired information and adopting a semantic description, essential for the representation of the artefact where data and entities are linked in a relational system. HBIM can be defined as a useful information system to enrich the knowledge about an existing building and it allows to manage heterogeneous data e.g. geometric, historical, thematic, etc. trying to put in order and combine them to enhance the heritage documentation. In addition, in field of restoration, a HBIM system represents an efficient tool for protection and conservation monitoring in order to prevent damage situations and it's also advantageous for decay analysis under a creation of a thematic mapping.

\section{WORKFLOW}

\subsection{Data acquisition}

The workflow pipeline starts with the data acquisition developing to the creation of the 3D model. The ground-based photogrammetric survey of interior and exterior environments of the church is carried by the TLS Leica C10 basing on more scans made from different point positioning following a network schema (Figure 3).

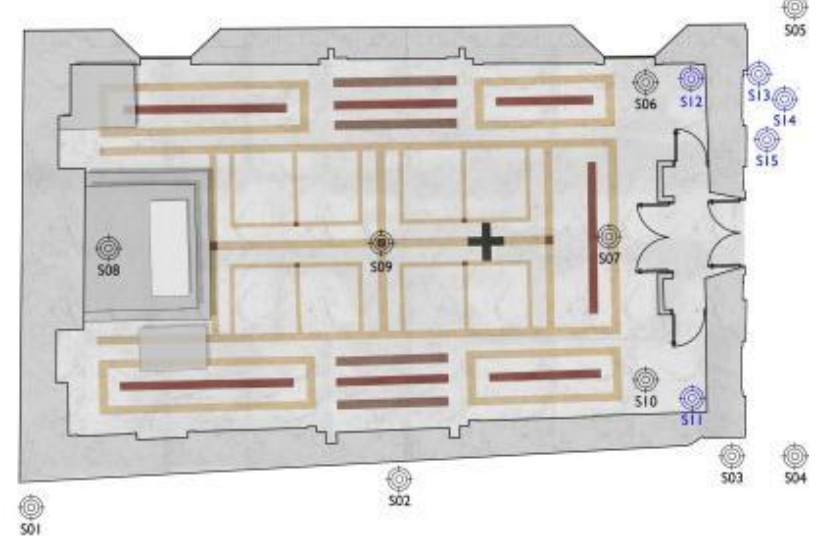

Figure 3. The acquisition network schema

For interior environment, it has been created a reference system using targets. For the survey of exterior, instead, the reference system is based on the use of two tripods: the first with the laser scanner and the second one, a viewfinder positioned manually, that has been identified during a $360^{\circ}$ scan by the laser scanner. On each scanning position, $360^{\circ}$ panoramic photos are made by the reflex camera Canon D80, placed on the top of the tripod (Figure 4). Photos useful to texture the 3D model derived by laser scanner acquisition.

Aligning the points cloud through the software Cyclone and mapping them directly with the images from the photographic survey, and so getting a result of strong representative realism, it is possible to obtain the point cloud of the whole object for a $3 \mathrm{D}$ representation (Figure 5), managed with an absolute error of $0.003 \mathrm{mt}$, on Autodesk ReCap.
Operating some cutting planes of the 3D merged point cloud we have provided some classical graphical representations as prospects, vertical and planar sections.
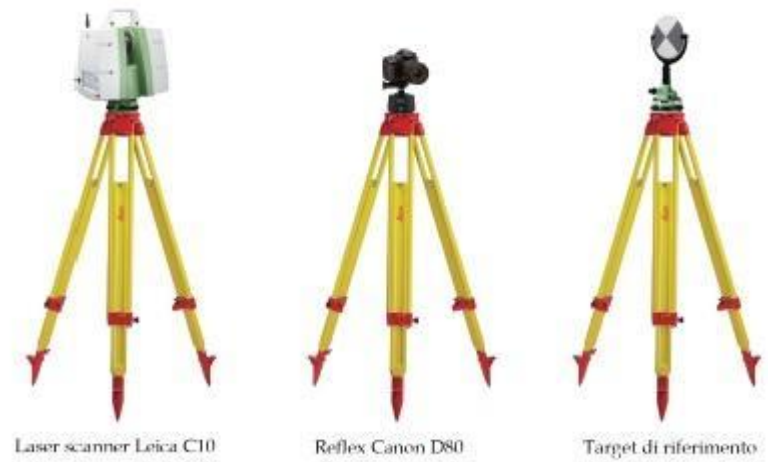

Figure 4. Topographic instruments for the surveying

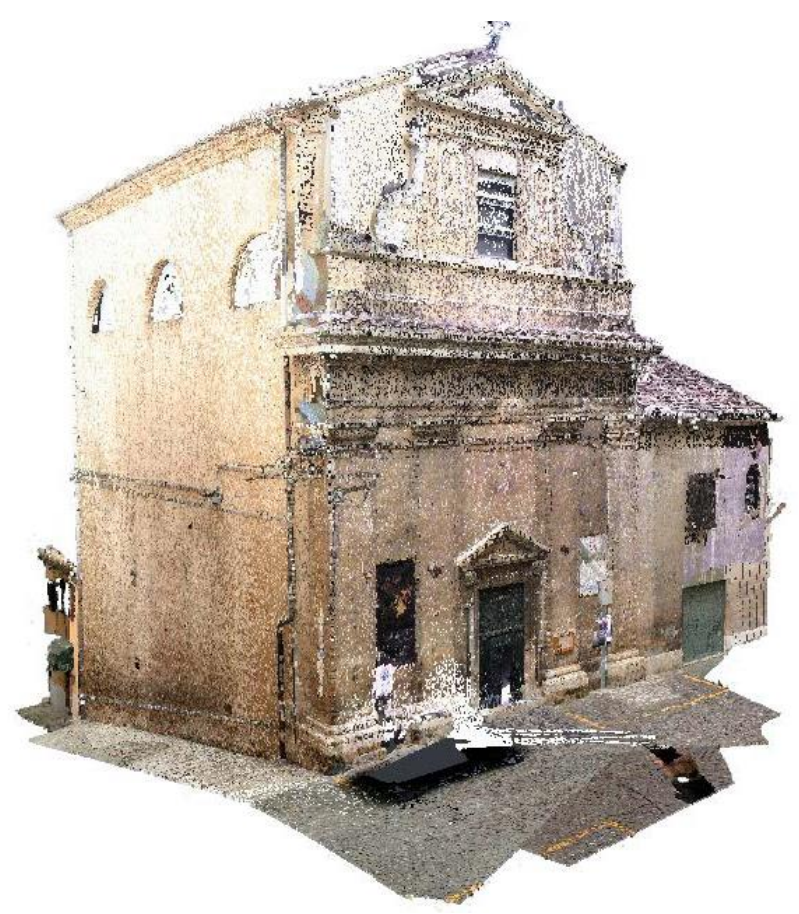

Figure 5. Points cloud textured by the images (by Onori F.)

\subsection{Material degradation analysis}

\subsubsection{External surfaces}

As regards external surfaces, it has been found that all the forms of alteration identified are mainly attributable to three factors / causes: mechanical erosion by atmospheric agents, such as rain and wind, accumulations of humidity and chemical attack by pollutants (mainly combustion powders due to the passage of cars in the adjacent streets and alleys). Analysing the facades individually one has:

- the South façade (or main facade) (Figure 6) is the one that presents more altered because for most of its surface are present superficial deposit phenomena mainly due to chemical attack by pollutants such as dust from combustion of the vehicles, and by the mechanical action of wind and heavy rain. For these same reasons the alteration in some parts of the façade also manifests 
itself in the form of efflorescence, superficial leaching, concretion and/or dripping (developed especially at the protrusions). There are also other forms of decay such as: the disintegration of mortar joints (also caused by the action of rain, wind and pollutants), the formation of biological patina, exclusively in small parts of the base of the columns and the lack of some parts of the frieze that collapsed as a result of the mechanical action of atmospheric agents. There are signs, finally, human interventions such as repair works carried out with techniques and materials incongruous with the original state of the monument and improper insertion of elements such as hooks and/or metal boards. Particular attention in the identification of decay pathologies has been placed in the analysis of the conservation status of the entrance portal: the stone materials and the brick elements have undergone mechanical erosion by atmospheric agents and there is a clear superficial deposit due to the pollution dust deriving above all from the combustion gases of vehicles passing nearby; the metal elements, made of wrought iron, due to heavy rain and lack of maintenance, show a general state of oxidation and corrosion with the formation of rust; the doorway, made of wood with two doors, is in a slight state of deterioration mainly due to lack of maintenance. This manifests an accumulation of humidity in particular in the basal part and the cracking of the wood in some places.

- The North and West elevations present three main types of alteration: superficial deposit, breakdown of mortar joints and formation of biological patina especially in coverage.

- The East side elevation is slightly different from the others mainly for a phenomenon of superficial alteration due to the rising damp in the lower part of the façade in contact with the ground.

\subsubsection{Internal surfaces}

From the analyses carried out, it emerges that the internal surfaces are substantially subject to the same pathologies and show a state of uniform degradation. All these problems are mainly caused to the lack of maintenance and accumulation of humidity due to the infiltration of water that percolates from some points of the roof. The effect of humidity on the west side of the building is evident, where, in correspondence of an injury to the roof, there is a large stain that has significantly damaged the original state of the plaster.

\subsubsection{Interventions for decay pathologies}

In relation to the pathologies encountered, the necessary interventions to restore the materials and surfaces of the monument were identified with the aim of preserving, and where necessary, restoring the original status of the "Chiesa della Pietà". By way of example of the methodology adopted, are described in detail below the interventions aimed at eliminating the most significant pathologies in terms of extension and damage caused relating to the main façade of the church (for which was created the HBIM modelling described below).

- Cleaning with compresses: the most widespread phenomenon in all the facades of the building is the superficial deposit caused by mechanical erosion (rain and/or wind), chemical attack by pollutants, formation of ice on the surface and runoff of rainwater. There is also uniformity of both causes and of intervention of this pathology with the phenomenon of the surface run-off. Surfaces subject to these types of problems can be restored by cleaning with compresses. This intervention is useful for the removal of soluble salts and to reduce the stains of copper or iron oxides. The compresses consist of absorbent clays mixed together with water and, for this reason, it is avoided to apply in direct contact with the surface chemicals that could be aggressive for the substrate. However, it should be
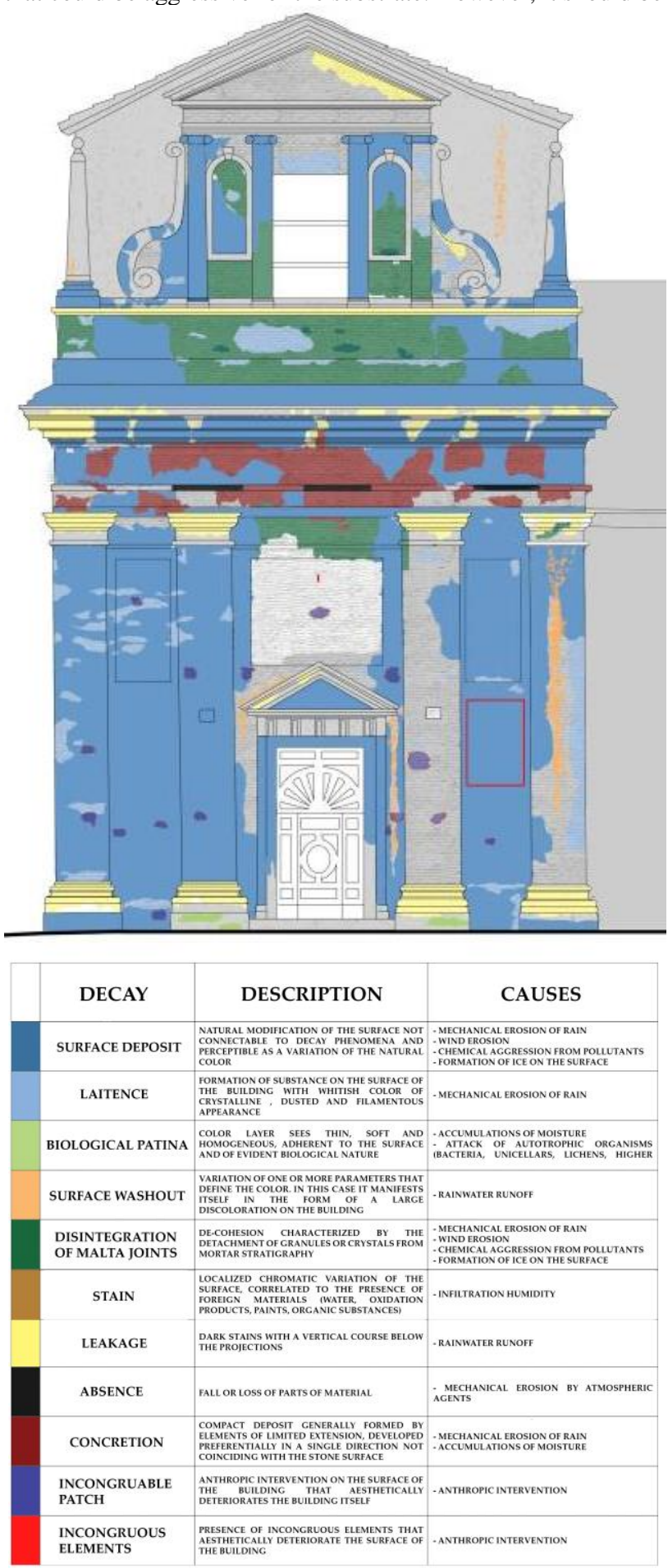

Figure 6. Main façade: thematic map of the material decay and related descriptive legend (Onori F.)

considered that these packs are not suitable for removing thick crusts. Moreover, if there are porous and not very cohesive surfaces, to avoid irreversible damage, it is advisable, before using the pack, to apply a layer of Japanese paper or klinex. In the case where efflorescence is present on the surface, it is 
advisable to provide their mechanical removal beforehand by means of deionized water.

- Grout joints grouting: This procedure is used to break down the joints of mortar caused by mechanical erosion (rain and / or wind) and by chemical aggression from pollutants. The intervention consists in the integration of the missing mortar portions and can be carried out using lime-based mixtures, provided that it has similar strength requirements to that of the mortar present in the building. The purpose of this intervention is to preserve the wall curtains from possible degradation phenomena (infiltrations), to guarantee better static performance of the masonry and to restore to the wall texture the aesthetic continuity that has disappeared over time. Before proceeding with the intervention, the non-consistent parts are removed also by means of soft brushes and a first surface wash is carried out. Then it is advisable to wet the surface to be treated with clean water and after having moistened all the joints, proceed with the application of the mixture in successive layers. For the preparation of the mixture it is possible to use materials such as hydraulic lime, sand or other minerals. Is recommend the use of natural hydraulic lime mixed with sand, especially for the deep areas to be restored. For the final part the lime putty can be used.

- Stucco and molding integration: the aim is the consolidation and reconstruction of the stone moldings and of the damaged decorative elements mainly present on the wall of the main façade. - Integration of stuccos and moldings: the intervention is aimed at consolidating and reconstructing the stone moldings and damaged decorative elements (mainly present on the masonry of the main façade) of which restoration is not possible through the relocation of the original elements. First of all it is advisable to remove the inconsistent material present on the surface (residual debris). Subsequently, if deemed appropriate, it is possible to put on a support reinforcement to prevent the stucco from deforming and to ensure that it adheres well to the support. Then proceed with the integration based on hydraulic lime (or plaster for the interior) and if necessary is possible add acrylic resins. It is possible to add natural pigments to obtain a dough that is as close as possible to the real as regards the particle size. The moldings must be reintegrated in successive layers. If is required the entire reconstruction, it is necessary to prepare some metal shapes that take up the original profile to recreate.

\subsubsection{Restoration project}

Once acquired the geometric and material survey of the artefact, a series of investigations have been carried out to assess the surfaces and material decay of the external façades and internal environments. Then, for each found pathologies, a specific intervention of restoration and conservation (Franceschi, Germani, 2010) was identified in compliance with the UNINorMal 11182:2006 standard and the NorMal 1/88 Recommendations. Furthermore, some structural problems have been occurred, mainly due to the infiltrations of water that percolates from the roof: through some access points it has been possible to investigate and verify the presence of an advanced state of deterioration of the roof covering and of the wooden supporting structure of the roof. Given this condition, it was decided to hypothesize a complete replacement of the roof with new elements but typologically similar to the pre-existing ones. Only for the wooden trusses it is proposed, instead of the substitution, the restoration of the wood elements that compose it and the strengthening of the supports to the walls with metallic elements (Figure 7).

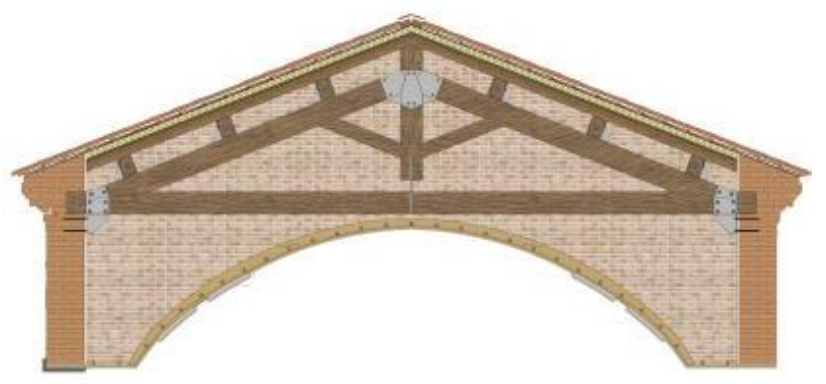

Figure 7. Roof construction details (by Onori F.)

\subsection{HBIM implementation}

After these analysis and assessment steps, we have arranged the 3D model in HBIM software suitable to develop a useful information system. Before the 3D modelling phase, a decomposing of the building is useful to implement a semantic classification of the architectural elements. Basing on a hierarchy of classes and subclasses, the dedicated database organizes the building components and their attributes, useful for the restoration process, storing the decay and materic characteristics of the architectural parts.

\subsubsection{Level of Development of the 3D model}

Before the 3D modelling phase, it's appropriate to establish which could be the LOD of the model. The LOD gives the degree of reliability of both the information integrated to the model and the characteristics of the geometrical elements.

According to the BIM Forum Level of Development Specification (2016) we have chosen to assign to this project the LOD 500. The LOD 500 provides for on-site check of the elements, confirming their shape, quantity, size and position (Garagnani, 2016). If this level is accurate, geometric data can be measured directly on the model and any type of information (materials, decay, historical data, etc.) may be added through external references. In this case we are talking about the "Level of Development" instead of "Level of Detail".

For these reasons we decided to adopt the parametric objectoriented modelling, basing on the use of pre-modelled object inserted in libraries of the HBIM software (Quattrini et al, 2015). Among software of direct modelling, we chose Rhinoceros to design 3D elements with complex shapes through operations of extrusion and revolution of composite profiles (Figure 8). These elements can be downloaded in the parametric model on software Autodesk Revit, used for the HBIM implementation.
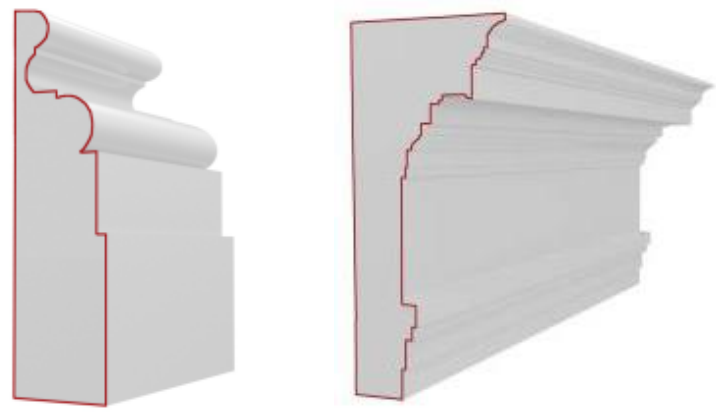

Figure 8. Examples of direct modelling processing 
From a conceptual point of view, an historic building can be decomposed in various modes and under different level of indepth analysis.

In this case it has been adopted three levels of geometry classification: the first for the representation of the building in the urban context, the second for the functional organization of the building areas, the latter one basing on the classification of architectural components. So, in deep, the level 1 coincides with the whole building. The spatial distribution allows to make a volumetric decomposition, identifying the interior areas for the functional classification of level 2. The third level is a division based on macro-elements such as: walls, floor, vault, etc. A subclass of this level describes the single components of each element, the micro-elements defining characteristics of the architectural style. (Figure 9)

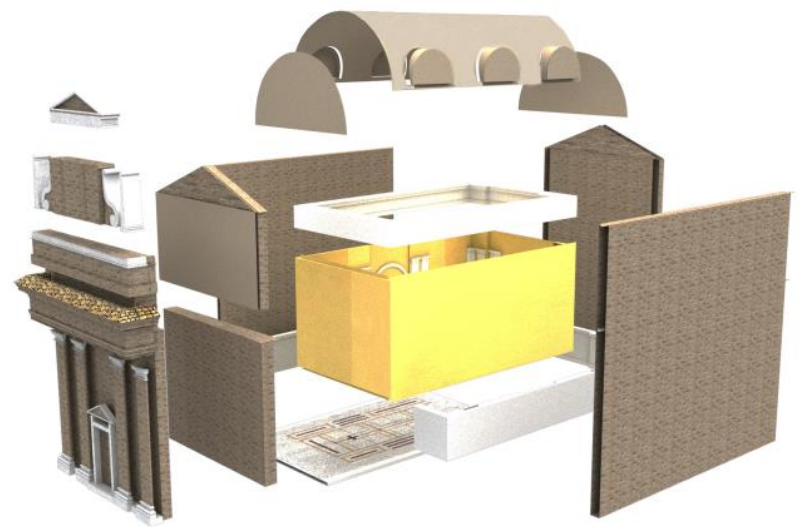

Figure 9. Exploded axonometry of the 3D model showing the architectural components

The design of the database architecture has a fundamental importance on the architecture of a HBIM, because the complexity and the usefulness of the information structure depends on it. According to the choice of LOD, the information structure of the monumental complex is built basing on the geometrical decomposition as illustrated above in the graph (Figure 10). In the same graph the classification explains better the functional logical process to the 3D modelling. This schema is useful to understand how decomposing the building and can be used as the basis of the next semantic classification.

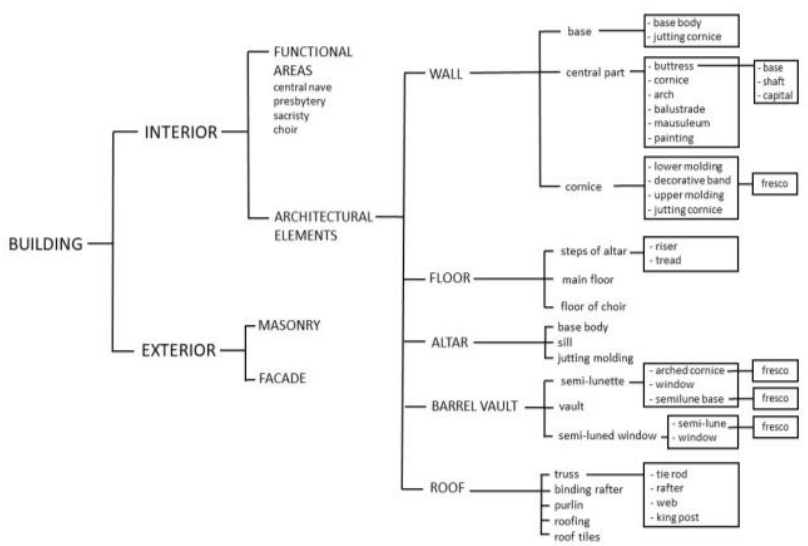

Figure 10. Graph of the geometrical classification and the architectural elements
In Revit the 3D model is built with its components as separated entities attributing to them an ID-code that can be identified univocally. We tried to build a unique flexible database collecting all the components of the building and dividing them in classes and subclasses. A hierarchical stucture that specifies the belonging of each entity to that part of the building. If the building has the ID-code " 00 ", interior environment has been assigned with a sub ID-code " 0001 ", while exterior has been indicated as "00 02". Following this hierarchy it becames simply to continue the assignment of the ID-code to all the entites belonging to parts or areas of both interior and exterior environment of the church. As the rusult we generated a treestructure database.

In Figure 11 you can see part of this classification concerning the exterior, in particular the facade element. Look also Figure 12 to understand better the labelled attribution to the elements in the facade model.

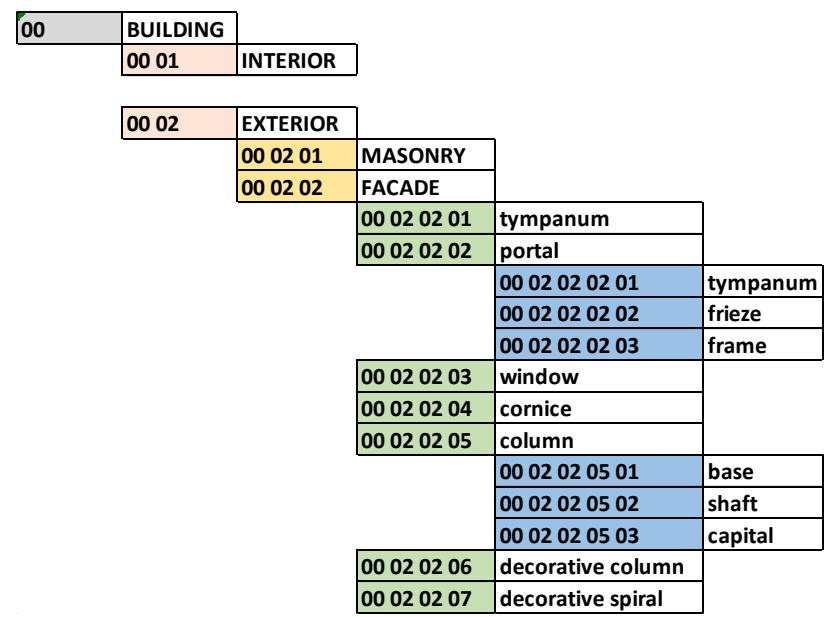

Figure 11. Tree-structure database with the ID-code assigned to each component

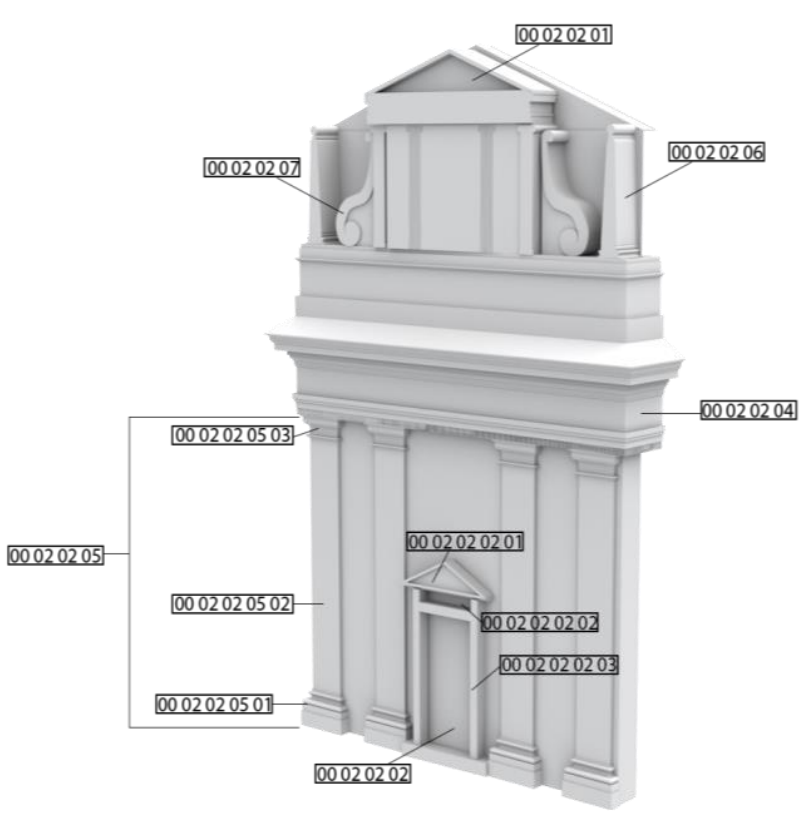

Figure 12. Labelling of the entities related to the 3D model of the facade 


\subsubsection{Semantic representation}

Semantic classification allows to develop a complete information system. In the field of $\mathrm{CH}$, the integration of semantic data with 3D models using BIM technologies (Scianna et al., 2014) allows to preserve an exhaustive level of information of the cultural good available for all stakeholders. Therefore, the use of Information and Communication Technologies (ICT) for documentation of $\mathrm{CH}$ became more and more diffused. In particular ICT technologies are very useful for restoration, conservation and fruition of cultural goods (Malinverni et al., 2018).

Strongly linked to the restoration is the problem of the conservation of information. The construction of a HBIM allows to preserve information about the $3 \mathrm{D}$ geometry of $\mathrm{CH}$ and its related semantic description saving information for subsequent needs. This structure allows to connect the 3D visualization of the building to an external database, in order to link the geometric 3D elements of the model with their corresponding table of attributes, which contains the semantic description.

In Revit, after assigned a ID-code to each element, you can add its known features, e.g. non geometrical attributes, as materials, type of decay, interventions, filling rows of the table collecting all the identified components. Selecting an identified element in the 3D model, its features can be also shown in an other table of contents. Where it needs, we might assign an other ID-code to these attributes to simplify their individuation in the whole parts of the 3D model.

The aim of this research is also to design new strategies that can take advantage of the benefits of HBIM also for less conventional activities: the decays have no specific building categories. However, the traditional orthogonal representation characterized by 2D patterns can't be semantically enriched by any parameter. This is the reason why the possibility of mapping in 3D the decay analysis was examined in detail.

3D modeling of decays in the HBIM platform ensures to enrich the related database with graphic and geometric data that can be effectively used to design and manage future interventions. The added value consists to associate new ID-code that identify the state of conservation of the materials and the detailed description of interventions needed to restore the building. (Figure 13).

\begin{tabular}{|l|l|l|}
\hline ID-code & DECAY & COLOR ATTRIBUTES \\
\hline D-01 & SURFACE DEPOSIT & blue \\
\hline D-02 & SURFACE WASHOUT & orange \\
\hline D-03 & LAITENCE & light blue \\
\hline D-04 & LEAKAGE & yellow \\
\hline D-05 & ABSENCE & black \\
\hline D-06 & CONCRETION & bordeaux \\
\hline D-07 & INCONGRUOUS ELEMENTS & red \\
\hline
\end{tabular}

Figure 13. ID-code attributing to the material decay (legend of the Figure 14)

In order to do that, the use an adaptive component was proposed: it is a particular object that can be adapted to the surface of the 3D model. In this way the thematic mapping of the material decay, analysed before, is applied, for example, to the 3D model of the façade of the church (Fig. 14).

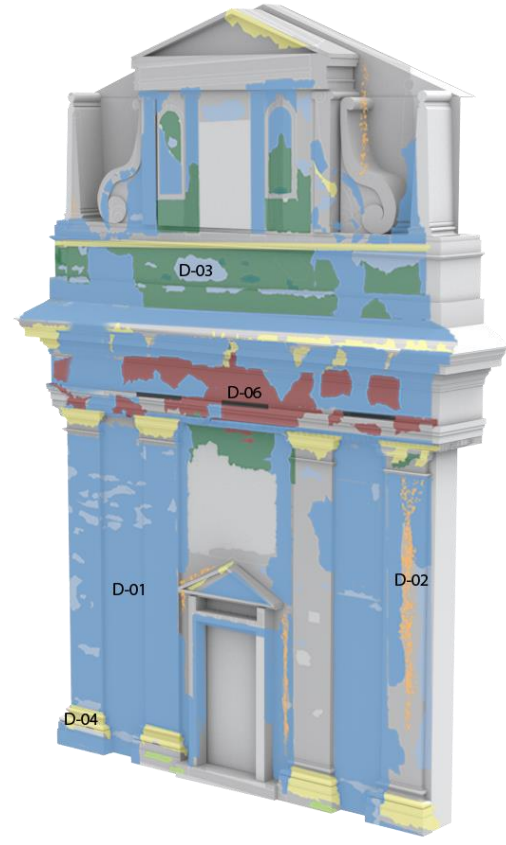

Figure 14. 3D thematic mapping of material dacay

\section{CONCLUSION}

The application carried out in this research shows that the use of HBIM in the cultural heritage restoration field is a good solution and has big potentiality for an efficient management and preservation project. Nevertheless, a widespread application of HBIM system to cultural heritage buildings requires a large investment in terms of costs, training and processing times. As shown by literature, HBIM simplifies the management of restoration phases to keep track of the interventions, constituting a sort of unique and searchable archive. The other advantage is the concept of interoperability so different experts can get involved and this allows the data sharing thanks to the usability typical of a HBIM software.

According to this new strategy in the restoration standards for architectural documentation it is possible to state that the approach in the present research allows to obtain 3D model that fits the need for the knowledge with analysis of the architectural heritage. All the survey process has been carried out using well known and consolidated technologies and methods for data acquisition and processing subsequently managed in commercial software and plug-in for the parametric modelling phase. Further analysis needs to be searched in the potentiality of HBIM systems, connected with the possibility that the database linked to the model could give for an improvement of knowledge.

The restoration of the Chiesa della Pietà in Fermo represents an example for methodological comparison, collaboration and exchange of information between various experts involved in diagnostic analysis, conservation and consolidation planning on that monumental historical building arising in a seismic area. A high Level of Development (LoD) results in an in-depth analysis of the artefact making a meticulous geometric decomposing of the architectural components. A manageable method of semantic classification basing on allocating an IDcode for an easier search permits to find out quickly the required information using a query language system. Thanks to the HBIM software the ID-code assignment might be extended, not only to classify the architectural elements, but also to identify attributes like material decay. In this paper we 
presented a solution applied to the main façade of the church, but this material decay analysis and classification can be adopted to the whole building.

\section{REFERENCES}

Lopez Facundo Jose, Pedro M. Lorens, Jose Llamas, Jaime Gomey-Garcia-Bermejo and Eduardo Zalama. 2018. A review of Heritage Building Information Modelling. Multimodal Technologies and Interaction 2(2), 21: np. https://doi.org/10.3390/mti2020021

Trebbi F., Filoni Guerrieri G. 2003, La Chiesa Metropolitana di Fermo, Andrea Livi Editore, Fermo

Maranesi F. 2002, Guida storica e artistica della città di Fermo, Andrea Livi Editore, Fermo

Fermo, Archivio Arcivescovile, Visita Maremonti 1573, II O 17, vol. I

Fermo, Archivio Arcivescovile, Visite pastorali 1838, II/6, Allegato A foglio 309r-v - 310r-v

Fermo, Archivio Arcivescovile, Inventario della Ven. Archiconf. Della Pietà della città di Fermo 1728, III s - 4 F/19

Fermo, Archivio Arcivescovile, Relazione ed inventario della Venerabile Archiconfraternita della Pietà di Fermo 1772, IIIs $4-\mathrm{F} / 20$

Penttilä, H.; Rajala, M.; Freese, S. Building information modelling of modern historic buildings. In Proceedings of the 25th eCAADe Conference on Predicting the Future, Frankfurt am Main, Germany, 26-29 September 2007.

Gómez-García-Bermejo, J.; Zalama, E.; Feliz, R. Automated registration of $3 D$ scans using geometric features and normalized color data. Comput.-Aided Civ. Infrastruct. Eng. 2013, 28, 98-111.

Akbarnezhad, A.; Ong, K.C.G.; Chandra, L.R. Economic and environmental assessment of deconstruction strategies using building information modeling. Autom. Constr. 2014, 37, 131144.

Bryde, D.; Broquetas, M.; Volm, J.M. The project benefits of building information modelling (BIM). Int. J. Proj. Manag. 2013, 31, 971-980.

Murphy, M.; McGovern, E.; Pavia, S. Historic building information modelling (HBIM). Struct. Surv. 2009, 27, 311327.

Volk, R.; Stengel, J.; Schultmann, F. Building information modeling (BIM) for existing buildings-Literature review and future needs. Autom. Constr. 2014, 38, 109-127.

Bruno N., 2014/2017, From survey to analysis for Cultural Heritage management: a new proposal for database design in $B I M$, Dottorato di ricerca in Ingegneria Civile e Architettura, Ciclo XXX
Franceschi F., Germani L. 2010, Manuale Operativo per il Restauro Architettonico, Tipografia del Genio Civile DEI, Roma

Norma UNI-NorMaL 11182:2006 (Beni culturali. Materiali lapidei naturali ed artificiali. Descrizione delle forme di alterazione - Termini e definizioni)

"Raccomandazioni NorMaL - 1/88. Alterazioni macroscopiche dei materiali lapidei: lessico", CNR-ICR, 1990, Roma

BIM Forum Level of Development Specification 2016

Garagnani, S. (2016), I Livelli di Sviluppo (LOD) nel progetto digitalizzato: La misura dell'informazione all'interno del percorso BIM. Building Smart Italia.

Quattrini, R., Malinverni, E.S., Clini, P., Nespeca, R., Orlietti, E., From TLS to HBIM. High quality semantically-aware $3 D$ modeling of complex architecture, Proceedings of 6th International Workshop 3DARCH "3D Virtual Reconstruction and Visualization of Complex Architectures", 25-27 February 2015, Avila, Spain. International Archives of the Photogrammetry, Remote Sensing and Spatial Information Sciences, Volume XL-5/W4, 2015, pagg. 367-374.

Scianna, A., Susanna, G., Paliaga, S., 2014. Experimental BIM Applications in Archaeology: A Work-Flow. In EuroMed 2014 -the International Conference on Cultural Heritage: Documentation, Preservation and Protection, 5 th International Conference, Euromed 2014, Lemessos, Cyprus, 3-8 November, 2014, pp 490-498.

Malinverni, E.S., Giuliano, A., Mariano, F., $3 d$ information management system for the conservation of an old deserted military site, in IMEKO International Conference on Metrology for Archaeology and Cultural Heritage, Cassino, Italy, October 22-24, 2018, pagg. 183-187 